http://revistainvestigacionacademicasinfrontera.com

\title{
Análisis del discurso fílmico a través del modelo dialógico simétrico/asimétrico: vídeo de la danza pascola de los indígenas yoreme de EI Fuerte, Sinaloa.
}

Mtra. Cecilia Guadalupe Martínez Solano, Mtro. Edgar Alberto Espinoza Zallas

ceciliamartinez.solano@gmail.com; espinoza.isd@gmail.com

Tecnológico de Monterrey, Campus Monterrey

\section{Resumen}

El presente trabajo consiste en un análisis del discurso fílmico, conformado por un vídeo de poco más de 6 minutos de duración, localizado en la página de Facebook llamada ITOM YOLEM JIAWI (Nuestros Sonidos Yoreme), utilizada por indígenas yoreme mayo de Sonora y Sinaloa. Se propone para ello un análisis semiótico, utilizando un modelo simétrico/asimétrico, diseccionando la muestra en tres partes con el fin de alcanzar mayor minuciosidad. Dicho ejercicio metodológico también destaca la presencia de un espacio fílmico y de isotopías como ejes temáticos recurrentes. Se pretende que el análisis sea útil para abrir una reflexión crítica sobre la construcción discursiva y visual de la identidad indígena y de las tradiciones de la cultura yoreme mayo, desde una narrativa fílmica.

Palabras clave: medios digitales, nuevas tecnologías, semiótica, discurso fílmico, indígenas yoreme mayo. 
http://revistainvestigacionacademicasinfrontera.com

\section{Introducción}

Para este proyecto se pretende el análisis del discurso fílmico en la forma de un vídeo con duración de 6 minutos con 36 segundos. El vídeo se localiza en la página de Facebook "ITOM YOLEM JIAWI (Nuestros Sonidos Yoremes)" (https://www.facebook.com/ITOM-YOLEM-JIAWI-Nuestros-Sonidos-Yoremes) donde fue colocado por primera vez el 3 de julio de 2016. El vídeo se titula "Paxköla sóonim. Barentina" (yolem-nokki o idioma yoreme), que se traduce al español como "Son de pascola. La Valentina". Cuenta a la fecha con 7, 571 reproducciones. La página de Facebook donde se encuentra es utilizada por los indígenas yoreme mayo de las comunidades de Sinaloa para interactuar, comunicarse y compartir contenidos culturales. Dicha página es administrada por un joven yoreme llamado Luis Antonio Hernández, originario de la comunidad de El Carrizo, en Ahome, Sinaloa. Hernández es activo en las actividades culturales de su región, y también en la comunidad yoreme de Ohuira, Sinaloa, donde ha participado en puestos tradicionales yoremes como fiestero y cantavenado. Se le atribuye a él la autoría de este vídeo.

La temática principal del vídeo es la danza del pascola, una de las danzas representativas de los yoremes, junto con la danza del venado y la danza del coyote. Las imágenes y sonidos se concentran en los actores principales de la danza, quienes son los músicos tradicionales y el danzante pascola, los cuales interpretan en este caso al son de la canción titulada "La Valentina". Los personajes predominantes son todos muy jóvenes: dos violinistas, un arpero y un niño danzante. Sobre los detalles que componen el discurso fílmico se profundizará en el análisis. Sin embargo, ahora mismo es útil destacar la presencia de texto en el filme, que nos proporciona información sobre el origen y los actores. El texto de apertura indica que se trata de un contenido original para la página "Itom Yolem Jiawi”, y esto se confirma en los créditos finales que le atribuyen la dirección del 


\section{http://revistainvestigacionacademicasinfrontera.com}

filme a dicha página. Aparecen también los hombres de los músicos. Violinista mayor: Alejandro Mendoza; violinista segundo: Ezequiel Bermudez (Pitito); arpa: Abraham Flores. No se menciona el nombre del danzante. Se revela en el texto el lugar de filmación: Los Capomos, El Fuerte, Sinaloa. El festejo (ceremonia): Cabo de año (responsorio). El cabo de año representa en la tradición católica el fin de un año de luto por un difunto.

Para el análisis se propone el uso de un modelo de análisis dialógico simétrico/asimétrico. También se ha de reflexionar acerca de la noción del espacio fílmico (tipos de espacio) presente en las interpretaciones posibles del discurso fílmico.

\section{Modelo dialógico simétrico/asimétrico}

El modelo metodológico seleccionado para el análisis del filme es el modelo propuesto por García y Finol (2006). Su uso se justifica a través de varios criterios de selección. El primero es que toma en cuenta la cualidad dialógica del texto fílmico como forma de comunicación de masas. La posibilidad de entender el discurso fílmico como comunicación dialógica - donde la interpretación de la audiencia receptora es una forma de retroalimentación que completa el ciclo comunicativo que le permite dialogar con el emisor - es particularmente ventajoso cuando se estudia discursos en redes sociales (Facebook). El segundo criterio es que este modelo plantea la introducción de Isotopías que construyen ejes temáticos a lo largo de la interpretación del discurso. Una isotopía podría ser, por ejemplo "tradición", "religión" o "familia". Estos ejes temáticos permitirían una clasificación temática transversal con otros discursos fílmicos (otros vídeos) u otros discursos en general (imágenes o texto). El tercer y último criterio consiste en la cualidad que le permite a esta estrategia integrar forma y contenido, que es la cualidad simétrica-asimétrica del modelo. En un primer nivel el diálogo se presenta asimétrico cuando es 


\section{http://revistainvestigacionacademicasinfrontera.com}

formulado por el autor emisor, y alcanza la simetría cuando es interpretado por audiencia receptora, aun cuando la interpretación se produzca diferida en el tiempo.

Este modelo fue diseñado por García y Finol (2006) a partir de varias propuestas teóricas de los estudios de la semiótica, y particularmente desde el modelo tríadico de Charles Sanders Peirce, que tiene su base en el concepto de semiosis desde una concepción tríadica del signo: Primeridad (el modo de significación como es), Segundidad (el modo de significación tal como es, con respecto a algo más) y Terceridad (el modo de significación de lo que es tal como es, trayendo un segundo y tercer elemento). La inspiración de esta teoría se encuentra en las tres columnas de la tabla de análisis, que corresponden a: los operadores sintácticos (escenadiálogo), los operadores formales (técnico-expresivos) y los operadores semánticos. Corresponden al contenido, la forma y la interpretación.

\begin{tabular}{|c|c|c|}
\hline \multicolumn{2}{|c|}{$\begin{array}{c}\text { Fragmentos fílmicos/Actividades situadas } \\
\text { El orden de lo pragmático }\end{array}$} \\
\hline \multicolumn{2}{|c|}{ El orden de lo sintagmático } & \multicolumn{1}{c|}{$\begin{array}{l}\text { El orden de lo } \\
\text { paradigmático }\end{array}$} \\
\hline Operadores sintácticos & Operadores formales & Operadores semánticos \\
\hline $\begin{array}{l}\text { Escena-Diálogo } \\
\text { características de la escena, de los }, \\
\text { objetos, el tiempo, diálogo, } \\
\text { adaptación del diálogo, tipo } \\
\text { de diálogo, ruidos, música, } \\
\text { desarrollo de la música. }\end{array}$ & $\begin{array}{l}\text { Encuadres, composición, } \\
\text { planos, contraplanos, } \\
\text { movimientos de cámara, } \\
\text { angulaciones, punto de } \\
\text { vista, ritmo, iluminación, } \\
\text { escenografía. }\end{array}$ & $\begin{array}{l}\text { Sentido sugerido, relación } \\
\text { interior/exterior en las } \\
\text { actividades, actores sociales, } \\
\text { roles temáticos, categorías } \\
\text { semióticas mensajes e e } \\
\text { isotopías, valores, discursos } \\
\text { sociales, el saber y el parecer. }\end{array}$ \\
\hline
\end{tabular}

Figura 1. El modelo dialógico simétrico/asimétrico. 
http://revistainvestigacionacademicasinfrontera.com

\section{El espacio fílmico}

De acuerdo a Neira Piñeiro (2003), el espacio fílmico "constituye, antes que nada, el marco o soporte físico de las acciones de un personaje. Todos los acontecimientos que se narran en un film aparecen siempre ubicados en un lugar." Este lugar en donde ocurre la acción y se definen las relaciones de los actores o personajes puede presentarse en distintas clasificaciones. Según la misma autora, existen dos grandes categorías en las cuales se catalogan los espacios: espacios fílmicos y espacios latentes.

\subsection{Espacios fílmicos o representación visual.}

El espacio escenográfico es entendido como el espacio teatral configurado por los elementos estáticos de la escenografía (muebles, objetos, fondos, decorados, etc.) así como algunos elementos dinámicos como luces y sonido. Son las características físicas del espacio. El espacio lúdico corresponde al espacio gestual, que se conforma a través de los gestos de los actores, su proximidad o alejamiento, confinamiento o apertura y los límites de sus espacios personales (zona íntima). Corresponde a la dinámica proxémica del espacio, que proporciona indicios de las relaciones que se exteriorizan por el uso del mismo. El espacio dramático corresponde a las distancias de la puesta en escena de una narrativa. Se establece mediante las relaciones actanciales.

\subsection{Espacios latentes y narrados o elementos no visuales}

Esta clasificación corresponde a los espacios alejados, que son introducidos a través del relato, pero permanecen fuera de campo. Generalmente se introducen mediante la narración verbal por un personaje. Los espacios psicológicos son aquellos que se sitúan en la interioridad de los personajes. Éstos se pueden 
http://revistainvestigacionacademicasinfrontera.com

identificar a través del uso de la escenografía, de los movimientos del personaje y los tipos de plano elegidos. También pueden representarse a través de imagen.

\section{Análisis de la muestra}

Se ha diseccionado el discurso fílmico en tres partes, con el fin de realizar un análisis más minucioso de sus elementos. La primera parte abarca del minuto 0:00 al minuto 2:12; la segunda parte desde el minuto $2: 13$ al minuto $4: 24$; y la tercera y última parte desde el minuto 4:25 al minuto 6:36.

La primera parte del análisis corresponde al modelo dialógico simétrico/asimétrico, que permite analizar el texto desde tres órdenes: el orden de lo pragmático, el orden de lo sintagmático y por último el orden de lo paradigmático. Esto es congruente con la lógica bajo la cual se construyó el modelo propuesto por García-Finol (2006), desde la teoría de la semiosis tríadica de Peirce. La segunda parte del análisis consiste en una interpretación de los espacios fílmicos y latentes que aparecen como soporte a la acción del discurso fílmico.

Fragmentos fílmicos/Actividades situadas: minuto 0 a minuto 2:12.

El orden de lo pragmático.

\begin{tabular}{|c|c|c|}
\hline \multicolumn{2}{|c|}{ El orden de lo sintagmático } & \\
\hline$\frac{\text { Operadores sintácticos }}{\text { Escena-Diálogo }}$ & $\frac{\text { Operadores formales }}{\text { técnico-expresivos }}$ & Operadores semánticos \\
\hline $\begin{array}{l}\text { Aparece un texto en } \\
\text { escena, con un fondo negro } \\
\text { y letras amarillas que dicen: } \\
\text { "Itom Yolem Jiawi". } \\
\text { Desaparecen y le sigue un } \\
\text { nuevo texto en letras } \\
\text { anaranjadas que dice } \\
\text { "Paxköla sóonim Barentina." } \\
\text { Desaparecen y surge un } \\
\text { nuevo texto en letras } \\
\text { blancas que dice: }\end{array}$ & $\begin{array}{l}\text { Fade in desde negro. } \\
\text { Aparece texto. Fade out } \\
\text { de texto y fade in tres } \\
\text { veces. El último fade out } \\
\text { no regresa al negro, } \\
\text { permite que las letras } \\
\text { tengan de fondo la } \\
\text { primera imagen y da } \\
\text { inicio con un plano } \\
\text { general de los músicos. } \\
\text { El ángulo privilegia un } \\
\text { punto de fuga en el lado }\end{array}$ & $\begin{array}{l}\text { Desde la apertura está } \\
\text { presente el tema de } \\
\text { "tradición", también algunos } \\
\text { elementos de "religión", } \\
\text { "comunidad" y "naturaleza". } \\
\text { La música alegre que suena } \\
\text { es un son pascola, es decir } \\
\text { que es música específica para } \\
\text { dicha danza. El texto de } \\
\text { apertura es de colores } \\
\text { intensos (amarillo, naranja) } \\
\text { que hacen su aparición en el }\end{array}$ \\
\hline
\end{tabular}




\section{http://revistainvestigacionacademicasinfrontera.com}

\begin{tabular}{|c|c|c|}
\hline $\begin{array}{l}\text { "Son de Pascola } \\
\text { La Valentina." } \\
\text { Las letras blancas } \\
\text { permanecen cuando en el } \\
\text { fondo se vislumbran } 3 \\
\text { músicos jóvenes: dos } \\
\text { violinistas y un arpero. } \\
\text { Desde el primer instante s } \\
\text { escucha la música de los } \\
\text { violines y ahora se sabe } \\
\text { que el origen son estos } \\
\text { músicos. Los tres usan } \\
\text { pantalones de mezclilla, } \\
\text { dos azules y uno negro. } \\
\text { Dos portan tenis y uno trae } \\
\text { sandalias. Los tres traen } \\
\text { camisa, dos de cuadros y } \\
\text { uno camisa lisa. Los tres } \\
\text { portan sombreros vaquero } \\
\text { un violinista usa uno con } \\
\text { una flor roja encima y el } \\
\text { arpero porta una flor } \\
\text { amarilla. Están sentados e } \\
\text { línea sobre una banca } \\
\text { rústica de madera, sobre la } \\
\text { tierra, en una construcción } \\
\text { de ramas. Cerca de ellos s } \\
\text { puede ver un tipo de altar } \\
\text { con flores. Los violinistas r } \\
\text { sostienen el instrumento a } \\
\text { estilo europeo, puesto que } \\
\text { apoyan el violín sobre su } \\
\text { pecho. Se ven unas } \\
\text { mujeres a lo lejos en el } \\
\text { fondo. El violinista de jean } \\
\text { negros porta también un } \\
\text { pañuelo rojo alrededor del } \\
\text { cuello. La música va } \\
\text { incrementando su ritmo, e } \\
\text { alegre y vivaz. A los } 45 \\
\text { segundos empieza a sona } \\
\text { algún tipo de cascabel o }\end{array}$ & $\begin{array}{l}\text { derecho de la pantalla, } \\
\text { hacia el final del recinto, } \\
\text { hacia el exterior. La } \\
\text { cámara se mantiene lo } \\
\text { más estática que le } \\
\text { permite el formato no } \\
\text { profesional (se presume } \\
\text { que está grabado con un } \\
\text { smartphone). Pasado el } \\
\text { primer minuto, se hace } \\
\text { un travelling hacia la } \\
\text { derecha, y el ángulo } \\
\text { cambia hacia un ángulo } \\
\text { picado para hacer un } \\
\text { close up en los pies del } \\
\text { danzante. Se mantiene } \\
\text { unos segundos y luego } \\
\text { hace un travelling hacia } \\
\text { arriba, revelando al } \\
\text { danzante, a la vez que } \\
\text { abre la toma al plano } \\
\text { general de nuevo. } \\
\text { Regresa a un close up } \\
\text { de las sonajas en las } \\
\text { piernas, y cambia } \\
\text { radicalmente el ángulo a } \\
\text { un contrapicado. } \\
\text { Privilegia al danzante en } \\
\text { plano general, conforma } \\
\text { un nuevo punto de fuga } \\
\text { con el danzante a la } \\
\text { derecha y el altar en el } \\
\text { punto de fuga. El } \\
\text { enmarque es a } 3 / 4 . \text { La } \\
\text { cámara sube de nuevo y } \\
\text { toma al danzante en } \\
\text { plano medio. }\end{array}$ & $\begin{array}{l}\text { vídeo. Primero se escribe } \\
\text { todo en yoreme, luego en } \\
\text { español, indicando que se } \\
\text { parte desde una cosmovisión } \\
\text { yoreme. Se construye un } \\
\text { misterio, una expectativa } \\
\text { cuando comienza la música } \\
\text { sin que veamos al danzante. } \\
\text { Su aparición es dramática, } \\
\text { porque el sonido remite a un } \\
\text { tercer músico más que un } \\
\text { danzante. La representación } \\
\text { tiene lugar en la ramada o } \\
\text { enramada, un lugar especial, } \\
\text { centro ceremonial de las } \\
\text { comunidades yoreme mayo. } \\
\text { Los músicos portan una flor } \\
\text { sobre su cabeza, que puede } \\
\text { ser una manera de } \\
\text { representar al itom atchay } \\
\text { oola (que significa "nuestro } \\
\text { padre viejo"), un tipo de } \\
\text { deidad sincrética que después } \\
\text { de la Conquista toma forma } \\
\text { en Jesucristo y en dios padre. } \\
\text { Es representado usualmente } \\
\text { por la sewa o flor, de colores } \\
\text { vivos, natural o artificial. La } \\
\text { sewa en su ciclo de vida } \\
\text { representa la eternidad del } \\
\text { itom atchay oola, que es una } \\
\text { deidad del monte que siempre } \\
\text { vuelve a la vida. Esta primera } \\
\text { secuencia es dominada por la } \\
\text { figura del niño danzante } \\
\text { pascola. La flor que porta en } \\
\text { la cabeza está justo arriba de } \\
\text { su coronilla, no en la sien y no } \\
\text { sobre un sombrero. En sus } \\
\text { piernas lleva una parte del } \\
\text { atuendo y un instrumento: los } \\
\text { tenábaris. Los tenábaris son }\end{array}$ \\
\hline
\end{tabular}




\section{http://revistainvestigacionacademicasinfrontera.com}

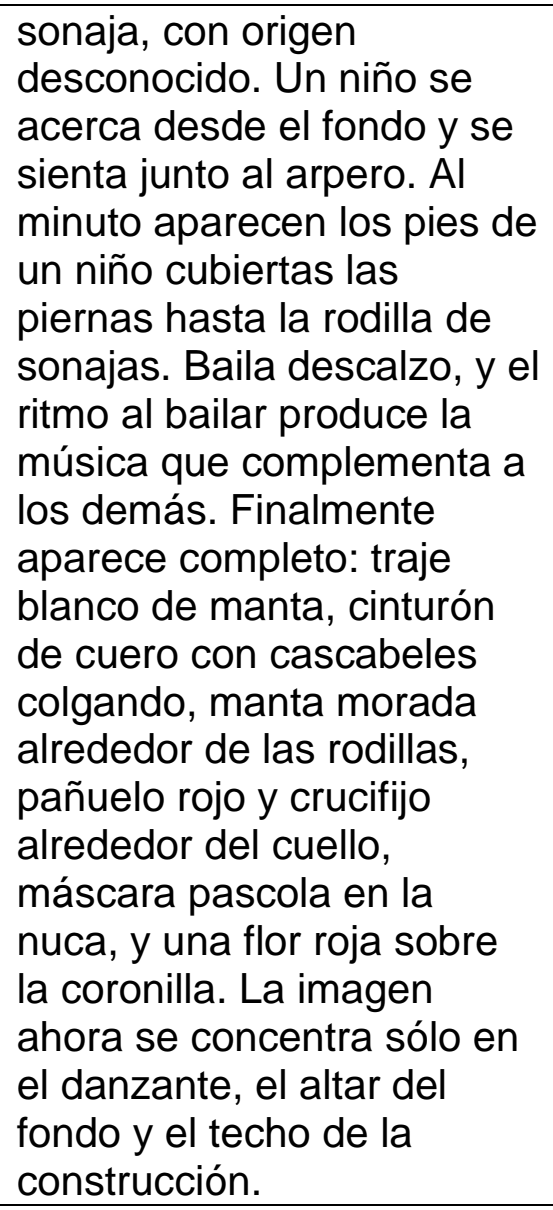

brazadas de hilos con
cascabeles hechos a mano
según la tradición utilizando
capullos de basëboli
(mariposa) y piedras de
hormiguero. También son una
conexión con la naturaleza, lo
que se reafirma en los pies
descalzos del niño, sobre la
tierra. Todo su atuendo hace
referencia a esto: su cinturón
de vaqueta, y su máscara
pascola que porta en la nuca
tiene pelo de vaca. Los
cascabeles que cuelgan de su
cintura también apoyan a
crear una secuencia musical
rítmica que emula los sonidos
del monte. De su cuello
cuelga una sencilla cruz de
madera que remite a la fe
católica colonizadora traída
de España, parte del legado
mestizo de México, incluso en
las comunidades indígenas.

brazadas de hilos con cascabeles hechos a mano según la tradición utilizando capullos de basëboli (mariposa) y piedras de hormiguero. También son una conexión con la naturaleza, lo que se reafirma en los pies descalzos del niño, sobre la tierra. Todo su atuendo hace de vaqueta, y su máscara pascola que porta en la nuca cascabeles que cuelgan de su cintura también apoyan a crear una secuencia musical rítmica que emula los sonidos del monte. De su cuello cuelga una sencilla cruz de madera que remite a la fe católica colonizadora traída de España, parte del legado las comunidades indígenas.

\begin{tabular}{|l|l|l|}
\hline \multicolumn{3}{|c|}{ Fragmentos fílmicos/Actividades situadas: minuto 2:13 al minuto 4:24 } \\
El orden de lo pragmático.
\end{tabular}




\section{http://revistainvestigacionacademicasinfrontera.com}

\begin{tabular}{|c|c|c|}
\hline . & $\begin{array}{l}\text { tercio derecho del } \\
\text { encuadre (ubicando allí } \\
\text { el altar). La alineación } \\
\text { angular es una } \\
\text { secuencia de intervalo } \\
\text { regular de elementos que } \\
\text { se repiten (sombrero, } \\
\text { camisa, instrumento, } \\
\text { manos), componiendo } \\
\text { una armonía visual. El } \\
\text { ángulo gira y de nuevo } \\
\text { observamos a los } \\
\text { músicos en plano } \\
\text { general, con la } \\
\text { construcción de ramas } \\
\text { en el fondo. La cámara } \\
\text { se mueve hacia la } \\
\text { derecha, regresa su } \\
\text { atención al danzante en } \\
\text { plano americano, para } \\
\text { luego bajar y hacer un } \\
\text { close up en las sonajas } \\
\text { de las piernas, con } \\
\text { énfasis en los } \\
\text { movimientos de los pies. } \\
\text { Después sube y realiza } \\
\text { un ángulo picado, que } \\
\text { permite ver la flor roja } \\
\text { justo en la parte superior } \\
\text { de la cabeza del } \\
\text { danzante mientras sigue } \\
\text { bailando. También } \\
\text { enfatiza la textura de la } \\
\text { tierra y el claroscuro que } \\
\text { se compone en la } \\
\text { sombra en contraste con } \\
\text { la luminosidad del día en } \\
\text { el exterior (fondo de la } \\
\text { toma). Unas ramas } \\
\text { verdes enmarcan la toma } \\
\text { a momentos. La cámara }\end{array}$ & $\begin{array}{l}\text { hacen reterencia a los } \\
\text { procesos de hibridación } \\
\text { cultural, tal como el uso de } \\
\text { botellas de Fanta y Squirt } \\
\text { como floreros. Los } \\
\text { muchachos yoreme (en el } \\
\text { fondo de la toma) utilizan } \\
\text { celulares y los músicos junto } \\
\text { con sus ropas tradicionales, } \\
\text { usan tenis modernos. Excepto } \\
\text { uno de ellos, que porta unas } \\
\text { sandalias de cuero, y el } \\
\text { danzante descalzo. Aquí } \\
\text { también se nos brindan más } \\
\text { indicios sobre la audiencia. } \\
\text { Quienes están más cerca, } \\
\text { también son jóvenes o niños, } \\
\text { y se les ve curiosos pero } \\
\text { incómodos. Esto podría } \\
\text { sugerir su interés en la fiesta, } \\
\text { pero su falta de entusiasmo } \\
\text { por participar como músicos o } \\
\text { danzantes, el desdén o falta } \\
\text { de compatibilidad moderna } \\
\text { hacia un ritual antiguo. } \\
\text { También observan con interés } \\
\text { y en silencio varias mujeres } \\
\text { mayores y en menor número, } \\
\text { hombres adultos. El uso de }\end{array}$ \\
\hline
\end{tabular}




\section{http://revistainvestigacionacademicasinfrontera.com}

\begin{tabular}{l|l|l|}
$\begin{array}{l}\text { violinista de la flor roja. Los } \\
\text { violinistas entrecruzan las } \\
\text { piernas colocando el tobillo } \\
\text { izquierdo sobre su rodilla } \\
\text { derecha. Esta secuencia de } \\
\text { la escena consecutiva } \\
\text { finaliza con el detalle de las } \\
\text { notas que marca el primer } \\
\text { violinista (el músico que } \\
\begin{array}{l}\text { aparenta menor edad) con } \\
\text { su mano izquierda. }\end{array}\end{array}$ & $\begin{array}{l}\text { Se hace un zoom in al } \\
\text { violín del joven de la flor } \\
\text { roja, y luego un primer } \\
\text { plano del instrumento; } \\
\text { después un close up de } \\
\text { su mano izquierda } \\
\text { marcando las notas en el } \\
\text { instrumento. }\end{array}$ & $\begin{array}{l}\text { las ramas verdes que decoran } \\
\text { la enramada como marco de } \\
\text { la toma no parece accidental, } \\
\text { pareciera un intento de } \\
\text { como marco de la dinámica. } \\
\text { Es interesante destacar que el } \\
\text { formato de interacción y uso } \\
\text { del espacio que proporciona } \\
\text { la enramada, es replicado en } \\
\text { Sonora y Sinaloa en fiestas, } \\
\text { reuniones familiares e incluso } \\
\text { en restaurantes - es decir, es } \\
\text { común ir a una fiesta o cena } \\
\text { que tenga esta distribución de } \\
\text { los asistentes, con músicos, } \\
\text { comida o un homenajeado en } \\
\text { el centro - }\end{array}$ \\
& &
\end{tabular}

\begin{tabular}{|c|c|c|}
\hline \multicolumn{3}{|c|}{$\begin{array}{l}\text { Fragmentos fílmicos/Actividades situadas: minuto 4:25 al minuto 6:36 } \\
\text { El orden de lo pragmático. }\end{array}$} \\
\hline \multicolumn{2}{|c|}{ El orden de lo sintagmático } & El orden de lo \\
\hline$\frac{\text { Operadores sintácticos }}{\text { Escena-Diálogo }}$ & $\frac{\text { Operadores formales }}{\text { técnico-expresivos }}$ & Operadores semánticos \\
\hline $\begin{array}{l}\text { La tercera parte continúa } \\
\text { con la dinámica de la } \\
\text { secuencia anterior, en la } \\
\text { misma escena, espacio, } \\
\text { con los mismos actores y } \\
\text { música. Se permite ver a } \\
\text { mayor detalle los } \\
\text { movimientos de las manos } \\
\text { sobre los instrumentos. Hay } \\
\text { un énfasis en las flores } \\
\text { sobre los sombreros y en } \\
\text { las manos de los artistas. } \\
\text { En el minuto } 4: 35 \text { se } \\
\text { escucha un cascabeleo, }\end{array}$ & $\begin{array}{l}\text { Se realiza un zoom out } \\
\text { desde la mano del } \\
\text { violinista y pasa a un } \\
\text { plano medio del segundo } \\
\text { violinista y el arpero. La } \\
\text { cámara se re ajusta y } \\
\text { vuelve al plano general } \\
\text { que abarca a todos los } \\
\text { músicos con la pared de } \\
\text { ramas en el fondo. Hay } \\
\text { un ligero ángulo que } \\
\text { coloca la salida, el } \\
\text { exterior de la } \\
\text { construcción (la luz) }\end{array}$ & $\begin{array}{l}\text { La figura dominante de esta } \\
\text { secuencia son los tres } \\
\text { músicos tradicionales: los dos } \\
\text { violinistas y el arpero. Cabe } \\
\text { aclarar que al intérprete del } \\
\text { arpa se le denomina en estas } \\
\text { comunidades de esa manera, } \\
\text { como arpero y no como } \\
\text { arpista. Su arpa es diferente } \\
\text { del arpa occidental, aunque el } \\
\text { principio es el mismo. En esta } \\
\text { secuencia hay un énfasis en } \\
\text { las manos y en el uso del } \\
\text { instrumento. El violín no es }\end{array}$ \\
\hline
\end{tabular}




\section{http://revistainvestigacionacademicasinfrontera.com}

\begin{tabular}{|c|c|c|}
\hline $\begin{array}{l}\text { ve a centrar su atenc } \\
\text { os músicos, } \\
\text { icularmente el violinis } \\
\text { a pañoleta roja y el } \\
\text { ro. Más de cerca es }\end{array}$ & $\begin{array}{l}\text { da } \\
\text { día, y } \\
\text { en una } \\
\text { de ramas, } \\
\text { mea en el } \\
\text { is luces y } \\
\text { sombras. } \\
\text { atraviesa } \\
\text { nfirmando } \\
\text { on técnico } \\
\text { o, es una } \\
\text { da, } \\
\text { Se realiza } \\
\text { segundo } \\
\text { arpero. } \\
\text { ano medio, } \\
\text { os } \\
\text { y la } \\
\text { e aprecia } \\
\text { aste de } \\
\text { rojos, } \\
\text { ico y } \\
\text { ovimiento } \\
\text { domina en }\end{array}$ & $\begin{array}{l}\text { I mismo en } \\
\text { de puesta } \\
\text { cumental o } \\
\text { ón. Aunque } \\
\text { es posible } \\
\text { e este } \\
\text { cular } \\
\text { de exponer } \\
\text { óvenes en la } \\
\text { lo cual es } \\
\text { uso de } \\
\text { ue se } \\
\text { rostros y en } \\
\text { ostro para } \\
\text { en las } \\
\text { destacar el } \\
\text { ica y el } \\
\text { lel joven } \\
\text { ondo niega } \\
\text { s músicos } \\
\text { stá activo en } \\
\text { e } \\
\text { sado), y } \\
\text { e intenta } \\
\text { rrra esta } \\
\text { er }\end{array}$ \\
\hline
\end{tabular}




\section{http://revistainvestigacionacademicasinfrontera.com}

\begin{tabular}{|c|c|c|}
\hline $\begin{array}{l}\text { comenzó, con los tres } \\
\text { músicos sin el danzante } \\
\text { (sólo permanece el sonido } \\
\text { de su cascabel, pero no su } \\
\text { imagen). La canción no } \\
\text { parece haber llegado a su } \\
\text { fin, pero aquí termina el } \\
\text { vídeo, abruptamente } \\
\text { cortando la música y la } \\
\text { imagen a un fondo negro. } \\
\text { Aparece texto: } \\
\text { DIRIGIDA POR: Itom Yolem } \\
\text { Jiaawi. } \\
\text { INTERPRETADA POR } \\
\text { Violinista Mayor } \\
\text { Alejandro Mendoza. } \\
\text { Violinista Segundo. } \\
\text { Ezequiel Bermudez. } \\
\text { (Pitito) } \\
\text { Arpa } \\
\text { Abraham Flores. } \\
\text { FILMADA EN } \\
\text { Los Capomos, El Fuerte, } \\
\text { Sinaloa. } \\
\text { Ceremonia: } \\
\text { Cabo de año } \\
\text { (responsorio). Fin. }\end{array}$ & $\begin{array}{l}\text { primer plano de ambas } \\
\text { manos manipulando el } \\
\text { violín. Luego vuelve a } \\
\text { abrirse la toma (zoom } \\
\text { out), primero un plano } \\
\text { medio del violinista, } \\
\text { luego se retoma el plano } \\
\text { general. Con un poco de } \\
\text { temblor la toma se abre. } \\
\text { Volvemos a ver a los tres } \\
\text { músicos en el plano } \\
\text { general. Fade out a } \\
\text { negro y empiezan a } \\
\text { aparecer los créditos en } \\
\text { cortinilla hacia arriba. La } \\
\text { música desaparece. } \\
\text { Aparece el texto, sube y } \\
\text { termina en negro (con la } \\
\text { palabra "responsorio" } \\
\text { aun flotando en el } \\
\text { negro). Fin. }\end{array}$ & $\begin{array}{l}\text { terminado la canción, lo cual } \\
\text { es consecuencia lógica de } \\
\text { cierta falta de planeación o } \\
\text { error de edición. En los } \\
\text { créditos no se le adjudica la } \\
\text { dirección del filme a ningún } \\
\text { individuo particular, lo cual } \\
\text { puede indicar no sólo una } \\
\text { labor colectiva sino una } \\
\text { mentalidad colectiva } \\
\text { intrínseca en el individuo } \\
\text { yoreme que transmite el } \\
\text { discurso. Sin embargo, sí hay } \\
\text { un reconocimiento nominal de } \\
\text { los músicos y del lugar de } \\
\text { filmación. Esto también es } \\
\text { congruente con la lógica } \\
\text { colectivista (se menciona a } \\
\text { los muchos y al lugar de los } \\
\text { muchos, y se omite al uno). } \\
\text { En las líneas finales de texto } \\
\text { se otorga información sobre el } \\
\text { festejo que se representó. Se } \\
\text { trata de un "cabo de año", el } \\
\text { momento -según la tradición } \\
\text { católica - en que se levante el } \\
\text { luto por un difunto, } \\
\text { transcurrido un año de su } \\
\text { muerte. De esto podemos } \\
\text { inferir que el festejo es una } \\
\text { forma de ofrenda para un } \\
\text { difunto al cual se le llevaron } \\
\text { velas y flores en la enramada. } \\
\text { Es probable que este ritual en } \\
\text { particular se halla } \\
\text { transformado desde la religión } \\
\text { sincrética que practicaban los } \\
\text { yoremes previamente a la } \\
\text { Colonia, y que se halla } \\
\text { adaptado después a la } \\
\text { tradición católica del cabo de } \\
\text { año. }\end{array}$ \\
\hline
\end{tabular}


http://revistainvestigacionacademicasinfrontera.com

\section{Espacios del discurso fílmico}

El espacio escenográfico está constituido por una construcción cotidiana no artificial. Tiene lugar en la comunidad de Los Capomos (el capomo es un tipo de flor), en el municipio de El Fuerte, Sinaloa. Se ubica en el espacio sagrado de la ramada o enramada, en uno de los pocos centros ceremoniales yoreme mayo que permanecen. La construcción recibe su nombre precisamente por tratarse de techo y paredes formados por ramas. No tiene piso firme, sólo de tierra. Los músicos están sobre una banca de madera rústica, algunos espectadores se sientan sobre sillas de plástico. La luz es la luz del día exterior que penetra en el espacio desde los fondos abiertos y a través de las grietas de las paredes y techo.

El espacio lúdico está distribuido de una forma que sugiere familiaridad, cercanía social. Los músicos están muy cerca unos de otros, y su lenguaje corporal es muy semejante, producen una cierta mimesis entre sí -especialmente los violinistas-. Los espectadores también se mantienen cercanos unos de otros, en fila sentados mientras observan. Los únicos dos elementos que mantienen distancia de los demás son el altar y el danzante pascola, en el centro. Se ubican en una posición privilegiada, propia para ser contemplados por el resto, que les rodean. Esto sugiere veneración, respeto.

El espacio dramático se compone por el uso del espacio que hacen los actores dentro de una dinámica que es puesta en escena. Aunque la secuencia es cotidiana y de no ficción, la danza del pascola es un ritual y esto le brinda un carácter de puesta en escena. Los movimientos del cuerpo del danzante pascola, su ubicación con respecto a músicos y espectadores, todo ello es congruente con la danza como dinámica dramática.

Hay un espacio latente que se vislumbra a través del uso de símbolos religiosos. Todos los elementos que emulan la naturaleza intentan recrear el carácter sagrado 


\section{http://revistainvestigacionacademicasinfrontera.com}

del monte como antiguo espacio ceremonial. Los colores, las flores, las ramas, las hojas de palma, los capullos de mariposa, las piedras de hormiga, las pieles de vaca, todo referencia a la naturaleza como ente de veneración y de lo sagrado. El espacio de la comunidad trata de replicar el espacio de las plantas y los animales, con quienes los miembros de la comunidad se identifican. El otro nivel de espacio sagrado es el espacio católico que es referenciado a través de las cruces y veladoras. Este hace referencia al espacio del ritual católico, que es la iglesia (donde probablemente se ofreció ceremonia al difundo que se recuerda, un año atrás). Pero la iglesia brilla más por su ausencia que por otra cosa. Aunque se le referencia, no es necesaria como espacio físico, sino únicamente como anclaje con la religión mestiza.

El espacio psicológico puede percibirse a través de las expresiones faciales de los actores, particularmente en primeros planos y close ups. Se puede hablar de la construcción de un espacio psicológico colectivo, que está conformado por el uso del espacio físico, por las expresiones de los rostros, y se ve afectado por la música de arpa, violín, cascabel y tenábaris. La música es alegre y vigorosa, como lo es la danza, sin embargo, los espectadores y músicos permanecen silenciosos. El movimiento de fondo de algunos individuos también representa la cotidianidad informal del ritual. No es el mismo espacio psicológico de una puesta en escena de teatro, y aunque la representación no es intencional por parte del emisor del filme (no en un guion, al menos), sí hay intencionalidad por mostrar una psicología colectiva a través de la selección específica de momentos. Todo el filme es una introspección a la cotidianidad de una sique colectiva por esta comunidad yoreme.

\section{Conclusiones}

Se debe destacar que el discurso fílmico analizado fue una selección no arbitraria de un momento cotidiano con cierto grado de espontaneidad. La no arbitrariedad de 


\section{http://revistainvestigacionacademicasinfrontera.com}

la selección recae en el proceso de análisis de menor grado de profundidad del grupo de discursos fílmicos compuesto por todos los vídeos encontrados en la página de Facebook de Itom Yolem Jiawi (NUESTROS SONIDOS YOREMES). Se seleccionó el analizado, cuidadosamente por observarse en él la intencionalidad fílmica en la elaboración del discurso. Se puede suponer que el evento fue planeado con intención, pero la producción del vídeo se realizó sin un guion secuencial o técnico. A pesar de la falta de planeación e intencionalidad técnica, se observa también un uso intencional de recursos fílmicos con el fin de destacar significados específicos, con referencias a ciertos símbolos especiales para la tradición detrás de la danza. Se observa también que es posible encontrar muchas referencias isotópicas al tema de la naturaleza dentro del discurso. También se manifiestan los ejes temáticos de tradición, religión y comunidad, pero el tema de naturaleza es mucho más recurrente en el uso de símbolos y signos. Dicho tema se hermana a menudo con la presencia de símbolos que evocan a la significación de la identidad yoreme, de "el humano". Ello puede indicar una relación estrecha entre la construcción simbólica del hombre, del humano, del yoreme, en uno mismo en armonía con la naturaleza.

El vídeo parece tener la intención de mostrar la tradición ejecutada en activo por los miembros más jóvenes de la comunidad yoreme mayo, que todavía aprenden las técnicas de música y danza de su cultura. Esto puede deberse a que las danzas en tanto elemento de tradición pueden funcionar como un ritual de iniciación a la actividad tradicional, así como a ser miembros activos de la comunidad. Así también como una forma de resistencia y permanencia de lo que es esencialmente yoreme. Un análisis más profundo, complementado con prácticas interdisciplinarias que conjugaran la semiótica con un análisis crítico y antropológico podría vislumbrar de forma más íntegra la complejidad del ritual representado en el discurso fílmico analizado. 


\section{http://revistainvestigacionacademicasinfrontera.com}

Los espacios fílmicos posibles en el discurso son múltiples y referencian más allá del espacio físico. Por tanto, estos espacios hacen referencia a la existencia de un espacio psicológico colectivo, de un grupo que se identifica primero como colectivo y después como individuos. Es decir, dentro de la narrativa del discurso, a través de la visualización de la danza, se intenta visibilizar a los espacios sagrados de la colectividad yoreme, denotando que no predomina la importancia del individuo tanto como de la comunidad, que se aglutina en la práctica de la tradición.

Se observa en el discurso la presencia de signos de la cultura occidental tradicional y moderna. Por una parte, el uso de instrumentos como el violín y el arpa, pero en términos distintos y propios del yoreme (no tocan al estilo occidental). Por otra parte, objetos de la modernidad como jeans, tenis y botellas de refresco son incorporados en un contexto distinto del cual emergen, dentro de una tradición indígena. Incluso el sombrero vaquero, las camisas a cuadros, pañoletas, veladoras y cruces son producidos desde un paradigma occidental colonialista, y le brindan identidad mestiza a la identidad indígena. Sin dejar de notar que existe una reapropiación de lo occidental, donde éste siempre es utilizado y parte redefinido primero que nada desde lo que es indígena, lo que es yoreme. Ello puede indicar una manifestación de hibridación cultural y de resistencia por parte de un grupo colonizado, que aun así persiste en la resignificación de elementos colonizadores.

\section{Bibliografía}

- Finol, José Enrique; García de Molero, Írida; (2006). Semiótica del cine: Un modelo dialógico simétrico/asimétrico para el análisis del texto/discurso fílmico. Quórum Académico, Enero-Junio, 77-104.

- Baygo, Rosario (2011). La religión como elemento de unión de nuestro pueblo Mayo/Yoreme. 24 de noviembre de 2016, de JúPARE MAYO Sitio web: http://rbaygo.blogspot.mx/2011/03/la-religion-como-elemento-de-union-de.html 


\section{http://revistainvestigacionacademicasinfrontera.com}

- Camacho Ibarra, Fidel. (2010). Mayos: de la inversión del orden al reverdecimiento de los valles. 24 de noviembre de 2016, de La Jornada del Campo Sitio web: http://www.jornada.unam.mx/2010/08/21/trazos.html

- Neira Piñeiro, M. R. (2003). Introducción al discurso narrativo fílmico. Madrid: Arco Libros, c2003.

- Moctezuma Zamarrón, José Luis. (2001). De pascolas y venados: adaptación, cambio y persistencia de las lenguas yaqui y mayo frente al español. México: Siglo XXI.

- Van Dijk, Teun (1996). Análisis del discurso ideológico. Versión. Comunicación y Política, 6, PP.15-43.

- Van Dijk, Teun. (1999) Ideología. Una aproximación interdisciplinaria. Barcelona (España) Editorial Gedisa. 